\title{
The Influence of the Lower Stratosphere on Ridging Atlantic Ocean Anticyclones over South Africa
}

\author{
THANDO NDARANA \\ Department of Geography, Geoinformatics and Meteorology, University of Pretoria, Hatfield, South Africa \\ MARY-JANE BOPAPE \\ South African Weather Service, Pretoria, South Africa \\ DARRYN WAUGH \\ Department of Earth and Planetary Sciences, The Johns Hopkins University, Baltimore, Maryland \\ LIESL DYSON \\ Department of Geography, Geoinformatics and Meteorology, University of Pretoria, Hatfield, South Africa
}

(Manuscript received 10 December 2017, in final form 26 April 2018)

\begin{abstract}
The link between Rossby wave breaking and ridging Atlantic Ocean anticyclones in the South African domain is examined using NCEP-DOE AMIP-II reanalysis data. A simple composite analysis, which used the duration of ridging events as a basis of averaging, reveals that ridging anticyclones are coupled with Rossby wave breaking at levels higher than the dynamical tropopause. Lower-stratospheric PV anomalies extend to the surface, thus coupling the ridging highs with the lower stratosphere. The anomaly extending from the 70-hPa level to the surface contributes to a southward extension of the surface negative anomaly over the Namibian coast, which induces a cyclonic flow, causing the ridging anticyclone to take a bean-like shape. The surface positive anomaly induces the internal anticyclonic flow within the large-scale pressure system, causing the ridging end to break off and amalgamate with the Indian Ocean high pressure system. Lower-stratospheric Rossby wave breaking lasts for as long as the ridging process, suggesting that the former is critical to the longevity of the latter by maintaining and keeping the vertical coupling intact.
\end{abstract}

\section{Introduction}

As recently as at the time of writing this article, Durban, a South African city located along the eastern coast of the country, experienced heavy rainfall that led to devastating floods, ${ }^{1}$ which caused extensive damage to property, including hospitals, and loss of life. Pending a more detailed analysis of the event, an operational forecasters' synoptic map analysis at the South African Weather Service (SAWS) revealed that this

\footnotetext{
${ }^{1}$ See https://www.enca.com/south-africa/stay-indoors-durbaniteswarned.
}

Corresponding author: Thando Ndarana, thando.ndarana@up. ac.za extreme rainfall event was caused by a cutoff low (COL) pressure system that was associated with a ridging Atlantic Ocean high pressure system or anticyclone. In this context, the ridging anticyclone is defined as a closed Atlantic Ocean high pressure system that extends eastward to cross the $25^{\circ} \mathrm{E}$ meridian (further details are shown in Fig. 1 and discussed in section 2). The COL extended a low to the surface along the east coast of South Africa. The high pressure system ridged strongly south of the country causing a tight pressure gradient between the ridging high and the low at the surface. This caused a strong nearly perpendicular onshore flow and an abundance of moisture along the eastern coast, and in particular over the Durban region. As a result the city experienced in excess of $100 \mathrm{~mm}$ of rainfall in less than a 24-h period. This is an example of extreme rainfall events that are associated with ridging anticyclones. 
Day 1: Dominant systems subtropical highs

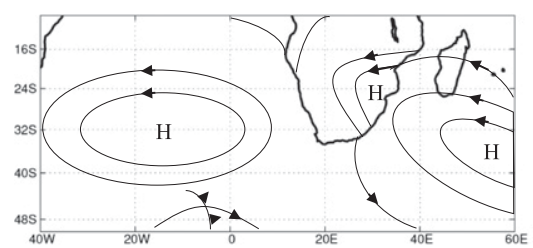

Day 4: Southerly meridional flow

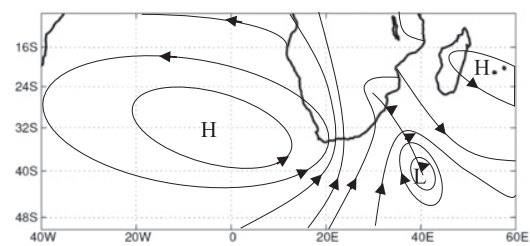

Day 2: Highs and approaching low

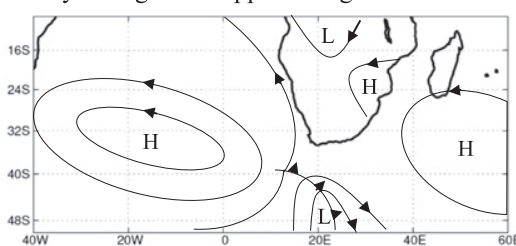

Day 5: Ridging anticyclone and easterly low

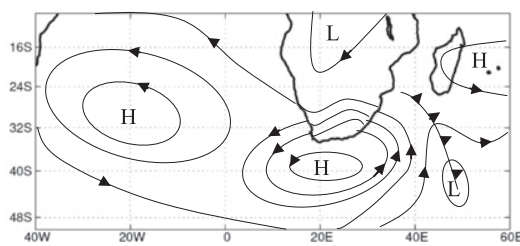

Day 3: Westerly low and easterly low

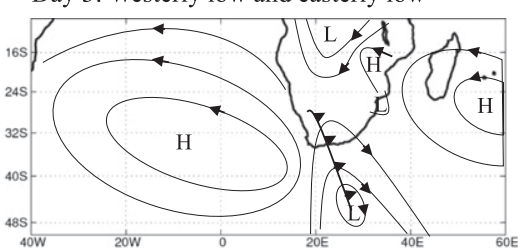

Day 6: Subtropical highs

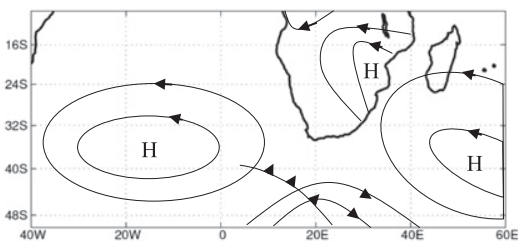

FIG. 1. A schematic illustration of a typical surface sequence of weather systems involving a ridging Atlantic Ocean anticyclone over South Africa. Day 1: Dominant subtropical anticyclones astride South Africa. Day 2: Subtropical anticyclones with approaching low and associated cold front. Day 3: A low in the westerlies drifts eastward to trail its cold front across the southern parts of South Africa. Day 4: The low moves away from the east coast of the country, while a strong meridional flow is observed across the subcontinent. On day 4 the Atlantic anticyclone begins to extend eastward toward Cape Town (the southernmost tip of Africa). Day 5: The leading edge of the ridging Anticyclone breaks off from the parent system to amalgamate with the Indian Ocean anticyclone. Day 6: The synoptic system structure reverts back to a configuration similar to day 1. [Adapted from Tyson and Preston-Whyte (2000).]

Several severe weather event studies over South Africa have included the important role that ridging anticyclones play as a moisture source for copious rainfall and even snow. These include Crimp and Mason (1999), who identified a tropical low in conjunction with a ridging anticyclone as responsible for heavy rainfall over eastern South Africa in February 1996. In this example, rainfall amounts in excess of $100 \mathrm{~mm}$ of rainfall was recorded along the coast and more than $90 \mathrm{~mm}$ were observed in the interior over the northeastern part of the country. In February 2005 event (Blamey and Reason 2009) more than $100 \mathrm{~mm}$ of rainfall fell in some areas along the eastern coast. Singleton and Reason (2007) identified a COL that accompanied a surface ridge as the main synoptic driver of a heavy rainfall event over the Eastern Cape province in 2002. Stander et al. (2016) described how the ridging Atlantic Ocean high supplied the moisture required for widespread snowfall to occur over South Africa in August 2012. Perhaps one of the most devastating extreme rainfall events in recent memory is the one that occurred in September 1987 (Triegaardt et al. 1988), again affecting the Durban area. During the time of the occurrence of this event more than $900 \mathrm{~mm}$ of rainfall fell within three days, with more than 300 people losing their lives and damage to property ran into billions of South African rands (van Heerden and Taljaard 1998). Over the Eastern Cape province ridging high pressure systems contribute $46 \%$ of the annual rainfall. COLs associated with the ridging anticyclone contribute an additional $16 \%$ of the rainfall in the Eastern Cape (Engelbrecht et al. 2015). Ridging anticyclones can also affect transport (e.g., Tyson et al. 1996), bring about conditions for transporting aerosols, for example (Tlhalerwa et al. 2005), and ocean dynamical processes (e.g., Rouault et al. 2000; Jury 2014) like upwelling, and possibly fog in Cape Town region (van Schalkwyk and Dyson 2013). Ridging anticyclones are clearly very important to the synoptic climatology of South Africa.

The question of why some Atlantic Ocean anticyclones climatologically extend eastward and ridge and others do not is open. Furthermore, the processes that inform the dynamics of ridging anticyclones, including their longevity, have also not been addressed. The objective of the current study is to understand some aspects of the climatological behavior of these weather systems and attempt to find their links to upper-atmospheric dynamical processes. The hypothesis that ridging anticyclones are linked to upperatmospheric dynamical processes is plausible because high-level potential vorticity (PV) anomalies induce cyclonic or anticyclonic flow at the surface, depending on the sense of the anomalies (Hoskins 1991). The structure of the paper is as follows: In the next section data and methods are outlined. In section 3 the results are presented: the climatological evolution of the horizontal fields, coupling of ridging anticyclones, and the stratosphere and surface behavior of the associated PV anomalies are discussed. A discussion and conclusions are given in section 4 .

\section{Data and methods}

\section{a. Data}

The data on which the 36-yr climatology is based are from the National Centers for Environmental Prediction 
(NCEP)-U.S. Department of Energy (DOE) AMIP-II reanalysis (NCEP-2; Kanamitsu et al. 2002) with 17 pressure levels at 6-hourly intervals. These data have a horizontal resolution of $2.5^{\circ} \times 2.5^{\circ}$, which translates into an average of $278 \mathrm{~km} \times 278 \mathrm{~km}$ in the domain of interest, defined here as the region bounded by $40^{\circ} \mathrm{W}$ and $60^{\circ} \mathrm{E}$ and the equator and $50^{\circ} \mathrm{S}$. This resolution is considered adequate for purposes of this study because ridging anticyclones are synoptic-scale processes.

Reanalysis data prior to 1979 are considered unreliable in the Southern Hemisphere (SH) because the inclusion of satellite observations in these products started at that time (Tennant 2004), therefore they are not included in the study. The climatology is formed using the years 1980-2016, with the first summer being December 1979 and January and February 1980. The variables used to calculate the diagnostics that will be outlined in sections $2 \mathrm{~b}$ and $2 \mathrm{c}$ are temperature, zonal and meridional wind components, mean sea level pressure (MSLP), and geopotential height fields.

\section{b. Methods}

\section{1) OBJECTIVE IDENTIFICATION OF RIDGING ANTICYCLONES}

Briefly, the evolution of the ridging Atlantic anticyclone is described as follows (see also schematic representation in Fig. 1; cf. Tyson and Preston-Whyte 2000):

- On day 1 , the circulation is dominated by a subtropical high pressure system, after which a low in the westerlies propagates eastward, in association with a cold front across the southern parts of South Africa, by day 3.

- As the low moves farther east, the Atlantic anticyclone extends eastward to cross the $25^{\circ} \mathrm{E}$ meridian and after a time it may form a bean-like shaped structure as it wraps around the South Africa and begins to organize an onshore flow over the coastal parts of the country. This onshore flow facilitates moisture fluxes along the onshore flow, as a result. These are day 4 processes.

- On day 5 the ridging anticyclone breaks off from the main Atlantic high and continues to propagate eastward and eventually integrates with the Indian Ocean anticyclone.

To identify ridging anticyclones in the South African domain (defined above) a simple 3-step objective algorithm is developed. This process exploits MATLAB's capabilities for approximating the vector indices of the latitudes and longitudes through which a contour passes within the domain. The domain was chosen to be large enough for all the South Atlantic high pressure systems to be considered, including those that extend eastward, as the ridging process takes place, but small enough to exclude other anticyclones on the subtropical high pressure belt and closed temperate cyclones.

The steps in the algorithm are outlined as follows:

1) For each 6-hourly time step, minimum and maximum MSLP values are identified and contours of MSLP from each minimum value to the corresponding maximum value are then calculated at $1-\mathrm{hPa}$ intervals. Only closed contours longer than 20 grid points are recorded as potentially belonging to an anticyclone. The 20-gridpoint restriction is aimed at excluding sub-synoptic-scale processes. While the contours do not lie exactly on the grid point, MATLAB can approximate the grid point closest to the contour. Using this feature, the number of grid points can then be approximated.

2) All concentric contours are grouped together starting with the largest one and ending with the smallest. Concentric contours are recorded as belonging to the same anticyclonic circulation (see days 1-3 in Fig. 1, top), and each one of the anticyclones is labeled accordingly.

3) The anticyclones are then categorized as ridging (see days 4 and 5 in Fig. 1, bottom), if at least the outermost contour extends from the South Atlantic Ocean across the $25^{\circ} \mathrm{E}$ meridian. This enables the calculation of the duration of each ridging anticyclonic event. Two centers of anticyclone activity have been identified in the South Atlantic Ocean (Jones and Simmonds 1994); this step automatically disqualifies the centers that occur upstream, closer to South America, as they would be too far west to ridge into the Indian Ocean.

\section{2) PV AND WAVE ACTIVITY DIAGNOSTICS}

Diagnosis of the vertical structure of PV requires its calculation on isobaric surfaces (Hoskins et al. 1985; Tamarin and Kaspi 2016), using

$$
\mathrm{PV}=-g\left(f \mathbf{k}+\nabla_{p} \times \mathbf{u}\right) \cdot \nabla_{p} \theta,
$$

where $\nabla_{p}$ is the horizontal gradient operator keeping the pressure constant (i.e., on isobaric surfaces), for which the derivatives are calculated using second-order differencing on a sphere, $g$ is gravitational constant, $f$ is the planetary vorticity, and $\nabla_{p} \times \mathbf{u}$ is the relative vorticity, where $\mathbf{u}$ is the horizontal velocity vector. The vertical derivatives of potential temperature $\theta, \partial \theta / \partial p$, are calculated using a second-order finite differencing method that takes unequal spacing of the standard pressure levels into consideration. 
To find the link between ridging anticyclones and the lower stratosphere the notion of Rossby wave breaking (RWB) will be considered. RWB is most clearly seen by examining PV contours on isentropic surfaces and is defined as the irreversible deformation and overturning of the contours such that $\partial \mathrm{PV} / \partial y<0$ (McIntyre and Palmer 1983). In this study, the PV values are obtained using Eq. (1) and linearly interpolated to the 330- and 350-K isentropic surfaces as in Ndarana and Waugh (2011). The actual level that might be important for the ridging high will first be established from a PV$\theta$ point of view and then the vertical PV anomaly structure will be considered. The RWB processes at the $350-\mathrm{K}$ isentropic surface will be used to explain the dynamical features found aloft. The rationale for choosing the $330-$ and $350-\mathrm{K}$ isentropic surfaces will become clearer in section 3 .

To categorize RWB in the Southern Hemisphere we follow Gabriel and Peters (2008) and Ndarana and Waugh (2011) and used the meridional component of a phaseindependent wave activity flux (Takaya and Nakamura 2001), given by

$$
\begin{aligned}
F_{y}= & \frac{\cos \phi}{2|\overline{\mathbf{V}}|}\left[\bar{U}\left(-u v-\frac{\phi}{f} \frac{1}{a} \frac{\partial v}{\partial \phi}\right)\right. \\
& \left.+\bar{V}\left(u^{2}+\frac{\phi}{f} \frac{1}{a} \frac{\partial u}{\partial \phi}\right)\right],
\end{aligned}
$$

where all the variables represent typical geostrophic variables. The uppercase symbols with overbars represent basic state fields, while the lowercase ones are the perturbations. In addition to making the quasigeostrophic assumption (which might limit its applicability over South Africa), this diagnostic assumes small-amplitude wave propagation, whereas RWB is a nonlinear process. Nonetheless, these diagnostics can still provide useful information about the nature of RWB, in particular its morphology. If the $\mathrm{PV}$ overturning region is dominated by positive (negative) $F_{y}$, then the RWB in question is anticyclonic (cyclonic) (Gabriel and Peters 2008; Ndarana and Waugh 2011).

The basic state flow is defined here as the seasonal average, for the seasons December-February (DJF), March-May (MAM), June-August (JJA), and SeptemberNovember (SON), and perturbations are deviations from it. Here $F_{y}$ is calculated for each 6-hourly time step and then a 48-h window running mean, a 9-gridpoint smoother, and a pressure weighted vertical average $\langle A\rangle$ [i.e., $\langle A\rangle=\left(p_{2}-p_{1}\right)^{-1} \int_{p_{1}}^{p_{2}}(A) d p$; Holton 2004] from 400 to $100 \mathrm{hPa}$ are calculated for reasons detailed in Gabriel and Peters (2008) and Ndarana and Waugh (2011).

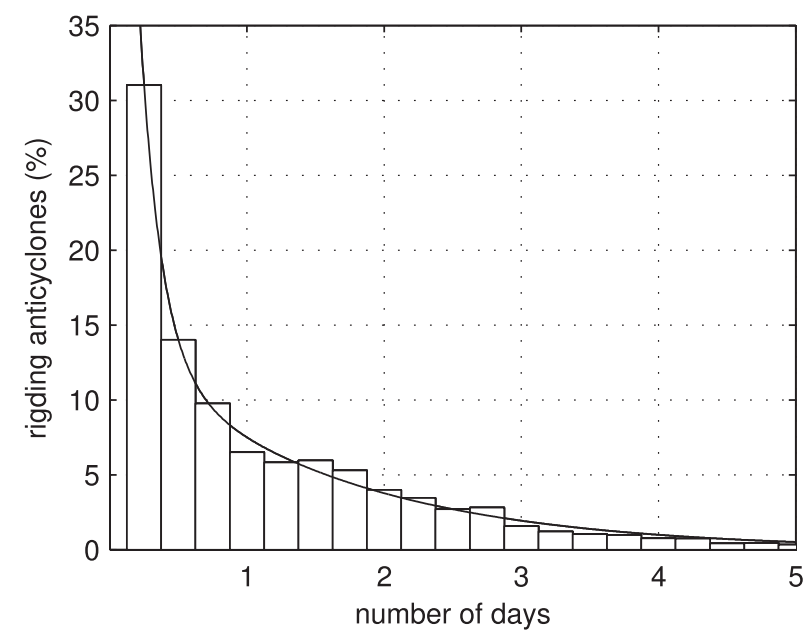

FIG. 2. Histogram showing the frequency of occurrence of Atlantic ridging anticyclones ( $y$ axis) as a function of duration in days. The curve is a fitted exponential function.

\section{Results}

\section{a. Horizontal evolution and lower-stratospheric links}

We first consider the horizontal evolution of ridging anticyclones and their possible link to stratospheric processes. The ridging events are first categorized according to how long they last. A frequency distribution of the events as a function of their duration in 6-hourly time steps is shown in Fig. 2. The effect of the duration, as will be seen later as well, is that the shorterlived events do not extend into the Indian Ocean as much as the long-lived events do. Thus the former are likely to only affect the southern parts of the country (Engelbrecht et al. 2015), whereas the longer-lived ones can at times impact coastal South Africa farther north (see examples in the introduction), and characterize wet spells with widespread rainfall over the country (Cook et al. 2004). The number of events decreases almost exponentially with increasing duration of event, as shown by the fitted exponential black curve in Fig. 2. Categorizing the events in this way is helpful because one expects that they would behave differently at different times for different durations. This categorization will form the basis of forming the simple composites.

Figure 3 shows the climatological mean evolution of the ridging anticyclones that have a 48-h duration together with PV (thick solid gray, thick solid black, and thick dashed contours) on the 350- and 330-K isentropic surfaces. There is a clear coevolution of the PV (thick black contour) and the mean sea level pressure fields, from $12 \mathrm{~h}$ before the inception of the ridging (Fig. 3a) to the end of it (Fig. 3f). Note that the evolution of these fields is plotted with respect to the evolution of the 

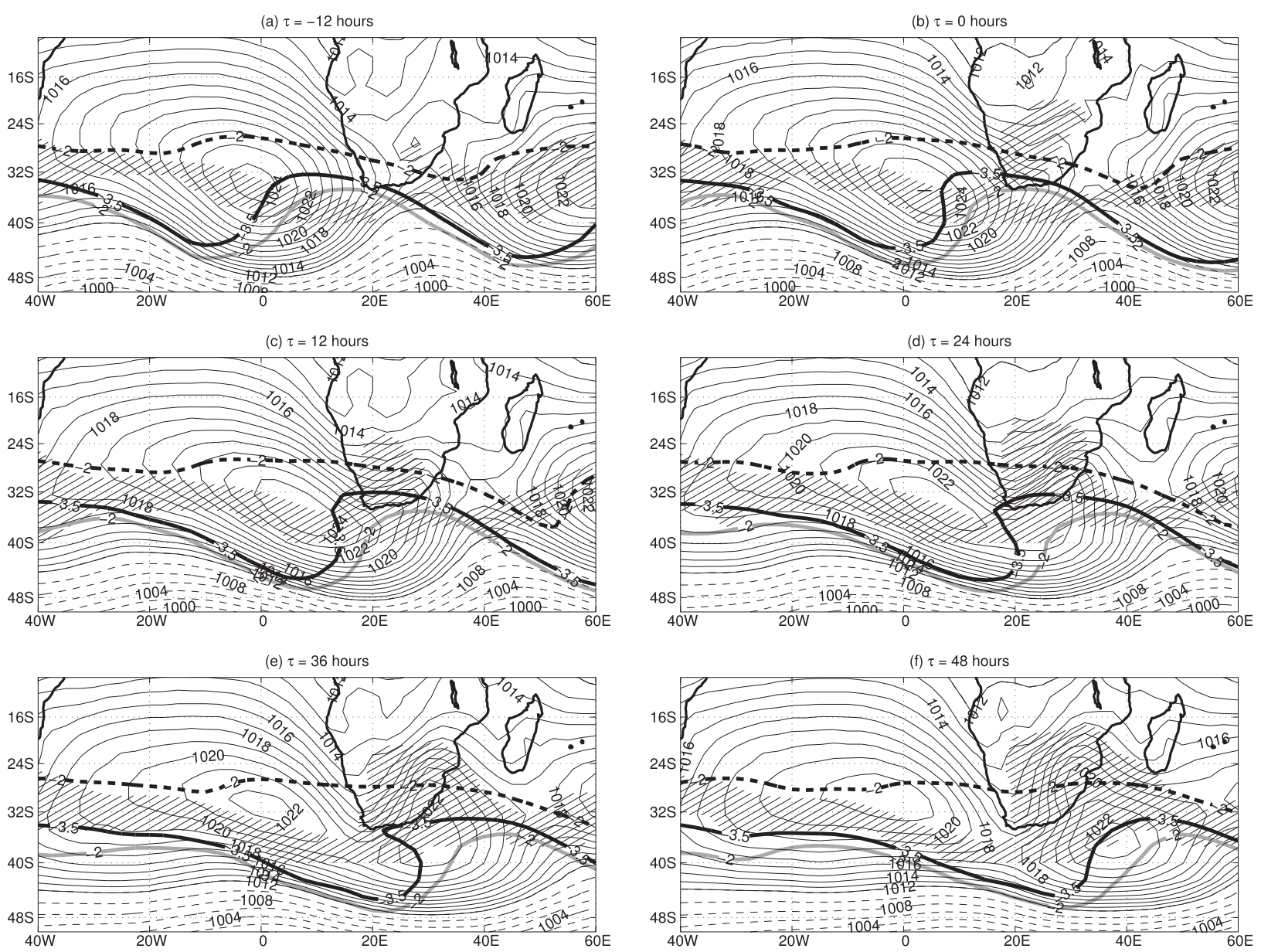

FIG. 3. Simple composite average of ridging Atlantic Ocean anticyclones (206 events) with a 48-h duration. Shown are MSLP (thin black contours for values $\leq 1012 \mathrm{hPa}$ and thin dashed contours for values $>1012 \mathrm{hPa}$ ), $\mathrm{PV}=-2$ (thick dashed black contour) and $\mathrm{PV}=-3.5 \mathrm{PVU}$ (thick solid black contour) on the $350-\mathrm{K}$ isentropic surface, and $\mathrm{PV}=-2-\mathrm{PVU}$ contour on the $330-\mathrm{K}$ isentropic surface (thick gray contour) for $\tau=$ (a) -12 , (b) 0 , (c) 12, (d) 24, (e) 36, and (f) $48 \mathrm{~h}$. MSLP contour interval is $1 \mathrm{hPa}$. The hatched regions show the standard deviation in MSLP.

ridging anticyclones, so that $\tau=0 \mathrm{~h}$ marks the inception of the ridging process (Fig. 3b), as shown by the Atlantic Ocean anticyclone beginning to extend east (Fig. 3b). This is the orientation of the ridging anticyclones that contribute to the all year rainfall region along the eastern coast of the Eastern Cape province, as discussed by Engelbrecht et al. (2015). PV overturning (thick solid black contour), signaling the beginning of wave breaking, appears in the fields at about $\tau=12 \mathrm{~h}$ (see thick solid contour in Fig. $3 c$ beginning to turn back on itself between the Greenwich meridian and $20^{\circ} \mathrm{E}$ ). As the ridging matures with time, the leading edge of the mean Atlantic anticyclone extends eastward into the Indian Ocean, crosses the $25^{\circ} \mathrm{E}$ meridian, and curls back (Figs. 3c,d), forming a bean-shaped structure. This brings moisture over the eastern parts of South Africa from the warm Indian Ocean. When coupled with systems such as a COL, a mechanism for raising the moist air would be provided, as noted before. Many of the cases cited in the introduction occur when the ridging high takes the position and posture shown in Figs. $3 \mathrm{c}$ and $3 \mathrm{~d}$.

The bean shape forms when the RWB is located just south of the South Africa (Fig. 3d). As the wave breaking propagates past the continent into the Indian Ocean, the ridging anticyclone breaks off from the parent Atlantic high, and propagates farther east to be integrated into the Indian Ocean anticyclone as clearly shown in Figs. $3 \mathrm{e}$ and $3 \mathrm{f}$. When the ridging comes to the end of its life cycle [at $\tau=48 \mathrm{~h}($ day +2$)$ ], the negative $\partial \mathrm{PV} / \partial y$ also disappears, while the broken-off structure amalgamates with the Indian Ocean high pressure system. Similar results were found (not shown) for the other categories, except for the shorter-lived ( $\leq 1$ day) ones.

The mean fields in Fig. 3 were produced by a simple composite average that only took the duration (see 

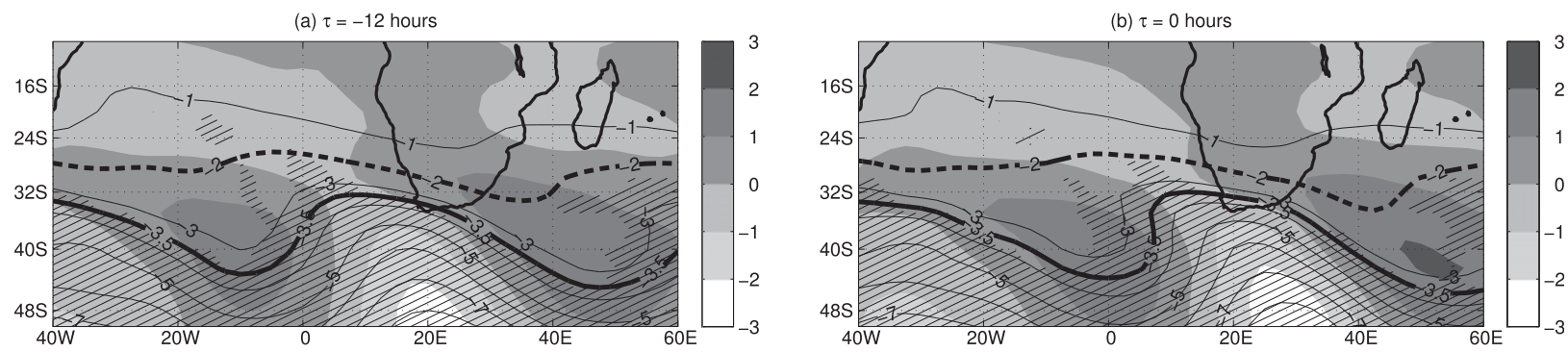

(c) $\tau=12$ hours
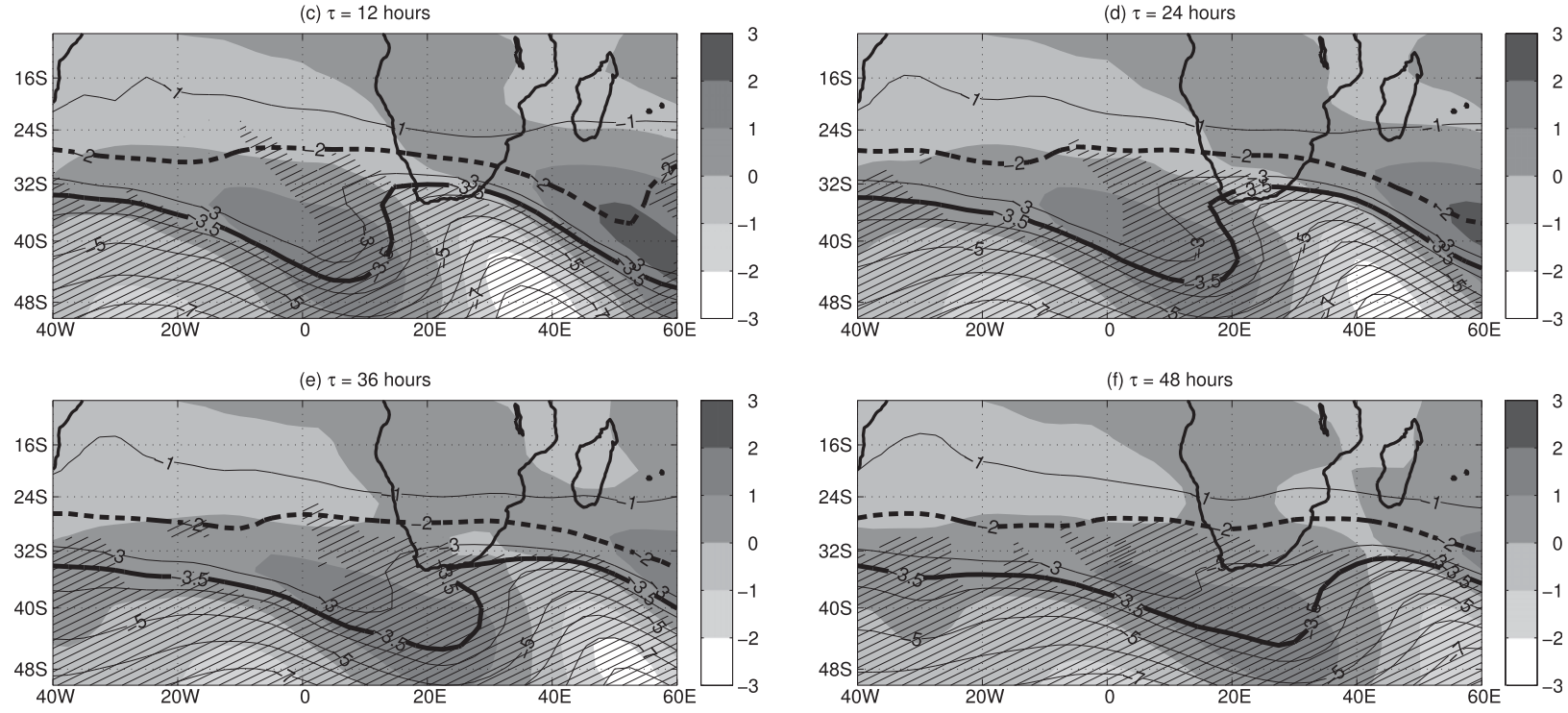

FIG. 4. Composites of PV contours on the 350-K isentropic surface associated with the ridging Atlantic Ocean anticyclones in Fig. 3. As in Fig. 3, the subtropical dynamical tropopause is highlighted by the thick dashed black contour (PV $=-2$ PVU). The thin solid black contours represent the PV on the 350-K surface, plotted at 1-PVU contour intervals. The hatched regions indicate areas of statistical significance at the $95 \%$ level. The fields are shown for $\tau=$ (a) -12 , (b) 0 , (c) 12, (d) 24, (e) 36, and (f) $48 \mathrm{~h}$.

Fig. 2) of the ridging anticyclones into consideration. The natural appearance of the ridging phenomenon in the mean field is largely informed by the fact that the location of the Atlantic anticyclone does not vary much in space. This is indicated by the low variance north of the hatched areas in Fig. 3, which indicate regions of variance between 5 and $7 \mathrm{hPa}$. The quasi-stationary nature of the Atlantic Ocean is most likely informed by the descending branch of the Hadley circulation, as revealed by local diagnostics (Schwendike et al. 2014).

As the South Atlantic anticyclone pressure system is quasi-stationary, and the ridging takes place adjacent to South Africa to the south, for the most part. In addition, the lower-stratospheric wave breaking is not assumed during the formation of the composites; it materializes automatically in a natural way from the composite averaging. This suggests that the RWB signal is, at the very least, climatologically associated with ridging events, just off the western coast. These wave-breaking events have also been identified in previous studies (e.g., Postel and Hitchman 1999; Berrisford et al 2007; Ndarana and
Waugh 2011; Song et al 2011). Therefore, the climatological presence of the breaking events in this region suggests that these events are organized so that they are generally collocated slightly southwest of Cape Town and also propagate eastward at more or less the same phase speed along the same "waveguide." If this were not the case, then the PV fields would be smoothed out in the lower stratosphere, as it is the case on the subtropical dynamical tropopause (thick dashed black contour in Fig. 3).

To develop an appreciation of the robustness of the RWB that is associated with the ridging discussed above, we now consider the entire range of PV contours on the 350-K isentropic surface together with the distribution of the PV anomalies on this surface and briefly contemplate how the latter form. Figure 4 shows the evolution these PV contours together with their associated PV anomalies (light and dark shading represent negative and positive anomalies, respectively) for the same time instances shown in Fig. 3. Clearly, the southern and northern lobes of the RWB are associated with positive 


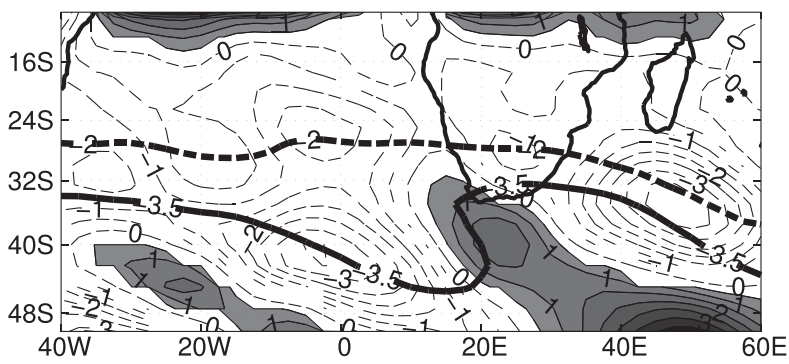

FIG. 5. The meridional component of the wave activity flux plotted with the PV $=-2$ - (thick dashed black contour) and -3.5-PVU (thick solid black contour) contours on the $350-\mathrm{K}$ isentropic surface at $\tau=24 \mathrm{~h}$ for ridging events that have a 48 -h duration (see Fig. 3). The positive values of wave activity flux (thin solid contours and shading) are associated with anticyclonic PV overturning (i.e., anticyclonic RWB).

and negative anomalies, respectively. This PV anomaly structure is brought about by southward isentropic transport of low PV air from the subtropics and northward transport of high PV air from the midlatitudes. Hence, this two-way transport of high and low PV air is facilitated by RWB. Note that the hatched regions indicate regions where the PV anomalies are statistically significant at the 95\% level (Brown and Hall 1999). It follows then that the statistical significance established in Fig. 4 suggests that the wave breaking that coevolves with ridging anticyclones in Fig. 3 is a robust feature of that development.

The lower-stratospheric wave breaking that is climatologically associated with ridging events is anticyclonic in nature, as clearly indicated by the shape of the overturning in the thick black contour in Fig. 3. This is further confirmed quantitatively by the fact that the anticyclonic PV overturning is associated with equatorward meridional wave activity flux [see Fig. 5 showing $F_{y}$ in Eq. (2) with $\mathrm{PV}=-3.5$ PVU (1 PVU $=$ $10^{-6} \mathrm{~K} \mathrm{~kg}^{-1} \mathrm{~m}^{2} \mathrm{~s}^{-1}$ ) on the $350-\mathrm{K}$ isentropic surface (Gabriel and Peters 2008; Ndarana and Waugh 2011)]; that is, regions of $F_{y}>0$ (gray shading in Fig. 5) correspond to regions of $\partial \mathrm{PV} / \partial y<0$ such that breaking is anticyclonic. Note again that Fig. 5 is produced by the simple averaging of the relevant fields assuming only that these fields are associated with ridging events that last for $48 \mathrm{~h}$ but shown at $\tau=24 \mathrm{~h}$. It follows that the presence of lower-stratospheric wave breaking is a robust feature in the lower stratosphere when ridging anticyclones occur at the surface.

\section{b. Vertical structure and coupling}

The coevolution of lower-stratospheric wave breaking and ridging anticyclones discussed above suggests that the two processes are tightly coupled. This subsection explores this issue further using vertical profiles of isobaric PV and geopotential height anomalies. To determine the anomalies, the zonal average in the domain of interest is calculated and subtracted from the original PV and geopotential height fields to obtain them. Their vertical profiles are constructed by taking the anomalies at $35^{\circ} \mathrm{S}$ (where the wave breaking and ridging occur; see Fig. 3) at each level and longitude to produce longitude versus pressure plots. We opted not to take the average over a range of latitudes because this tends to cloud the point to be raised here as we desired to understand what dynamically transpires when the climatological beanlike shape forms. These vertical profiles are shown in Fig. 6. Figures 3 and 6 should be interpreted together, observing that corresponding points in the evolution are on corresponding panels.

The evolution of the vertical profiles of PV and geopotential height anomalies (Fig. 6) is consistent with the evolution of RWB and ridging anticyclones. Before the ridging takes place, the Atlantic anticyclone pressure system appears to be coupled to the upper-air positive PV anomaly. This is indicated by the collocation of the vertical PV anomaly structure and that of the geopotential height anomalies. This PV anomaly extends down to the surface to the region of strongest positive geopotential height anomaly (i.e., just west of the center of Atlantic to about the eastern edge of the anticyclone; observe the location of the thick white contour between $20^{\circ} \mathrm{W}$ and the Greenwich meridian and at about $20^{\circ} \mathrm{E}$ relative to the thin black contours in Fig. 6a). East of this positive PV anomaly, there exists a negative anomaly (Fig. 6a). The latter also extends down to the surface to the region between the Atlantic and Indian Oceans high pressure systems. A westerly wave low-cold front system is found in this region, as shown by the negative geopotential height anomalies found there. In both structures the westward tilt with height is clear, which is characteristic of baroclinic systems (Charney 1947), and signals the extraction of eddy available potential energy from the mean flow (Holton 2004). Note also that the lower-stratospheric PV anomaly field appears before the breaking takes place. This preexisting PV anomaly arrangement would most likely be associated with undulations (see thick black contour in Fig. 3a) in the PV contours and, therefore, linear Rossby wave propagation.

As the breaking events propagate eastward, the strong lower-stratospheric PV anomalies are also advected eastward. The preexisting lower-stratospheric PV anomaly is elevated slightly (observe the vertical displacement of the 1.5-PVU anomaly contour in Fig. 6) and strengthened with time (as the appearance of the thick black contour and the wave-breaking wave propagates eastward), while its negative counterpart is lowered. This 

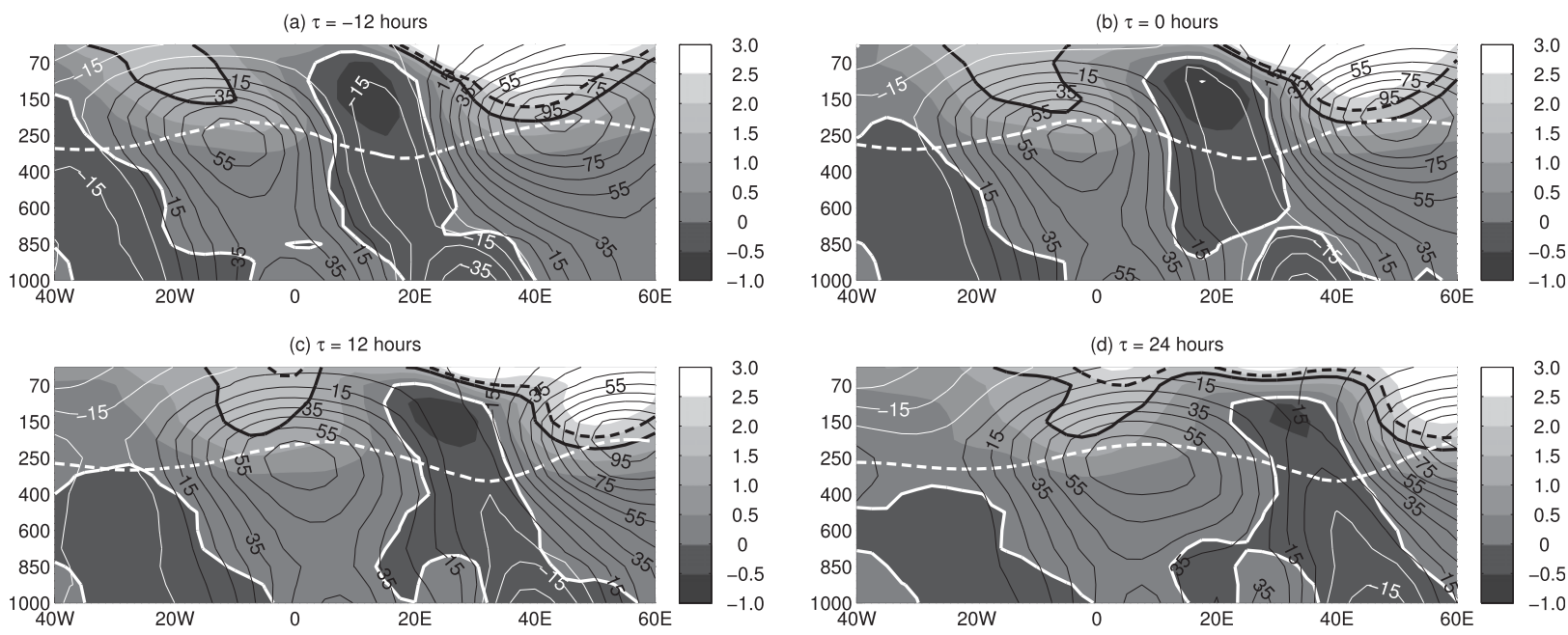

(e) $\tau=36$ hours
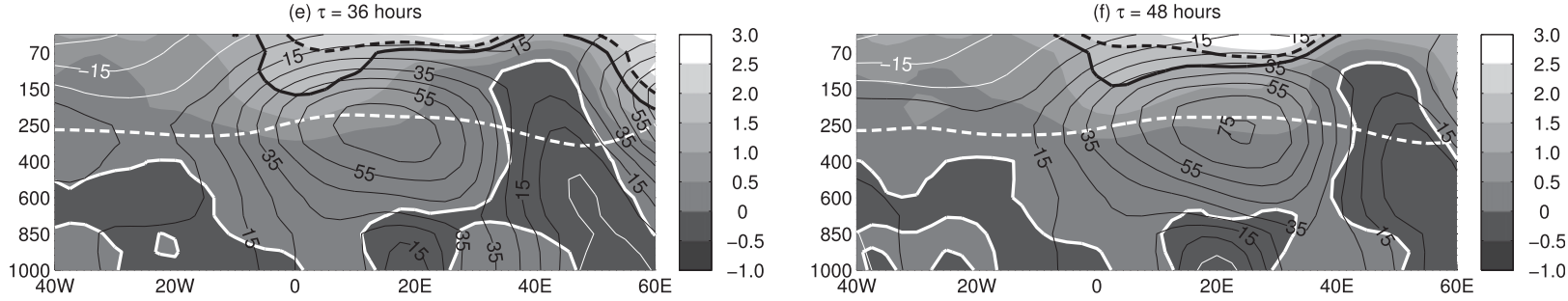

FIG. 6. Composites of vertical profiles of potential vorticity and geopotential height anomalies at $35^{\circ} \mathrm{S}$ associated with ridging Atlantic Ocean anticyclones in Fig. 3, with the thick dashed black, thick solid black, and thick solid white contours representing the PV anomaly contour levels 2, 1.5, and 0 PVU, respectively. The thick dashed white contour represents the PV $=-2$ PVU on the $350-\mathrm{K}$ isentropic surface, indicating the position of the subtropical dynamical tropopause. Darker gray shading represents the negative PV anomaly structure. The thin black and white contours represent the positive and negative geopotential height anomalies, respectively, plotted at intervals of $10 \mathrm{~m}$. The fields are shown for $\tau=$ (a) -12 , (b) 0 , (c) 12 , (d) 24 , (e) 36 , and (f) $48 \mathrm{~h}$.

stands to reason because, while the $350-\mathrm{K}$ isentropic surface appears to be quasi-horizontal, the isentropic surfaces below that level have a negative gradient with respect to decreasing pressure. Therefore the wave breaking occurring at these levels will tend to transport the low (high) PV air up (down) gradient, taking the sign convention of $\mathrm{PV}$ in the $\mathrm{SH}$ into consideration, in addition to advecting the alternating lower-stratospheric PV anomaly eastward.

It is clear from the from Fig. 6 that lower-stratospheric air that is advected southward continues to be important during the ridging process, until the ridging anticyclone amalgamates with the Indian Ocean high pressure system. At that point the lower stratosphere and surface are decoupled. The initiation of the ridging process is evident from $\tau=0 \mathrm{~h}$ (Fig. 6b) to $\tau=12 \mathrm{~h}$ (Fig. 6c) at near the surface eastward of $20^{\circ} \mathrm{E}$, as shown by the movement of the geopotential height anomalies. This movement of the geopotential height anomaly is preceded by a lowlevel positive PV anomaly forming there, which in turn is informed by eastward propagation of the wave breaking. This suggests that the lower-stratospheric wave breaking could be responsible for moving the whole positive PV structure, so that the low-level part of it can induce anticyclonic flow where it was not before.

As the system evolves, the interesting observation to make here is that the negative PV anomaly found upstream is important for ridging and it appears to be playing a role in inducing the cyclonic flow (trough) over the interior of South Africa, as the anticyclone takes the bean shape. As the ridging begins, the negative anomaly extends a tongue in a downward and westward direction ( $\tau=12 \mathrm{~h}$; Fig. $6 \mathrm{c})$. The tip of this tongue extends to the surface $(\tau=24 \mathrm{~h}$; Fig. $6 \mathrm{~d})$ and in some cases forms an isolated blob in the manner shown in Fig. 6f at $\tau=48 \mathrm{~h}$ and in others it remains attached to the main vertical negative PV anomaly structure. Note that this low-level negative PV anomaly does not extend to the lower stratosphere, and so it cannot originate aloft. Its origins will be discussed further in section $3 \mathrm{c}$ below.

The high-PV air starts reaching the surface as the ridging takes place (cf. Figs. $3 \mathrm{~d}$ and $6 \mathrm{~d}$ at $\tau=12 \mathrm{~h}$ ) and at $\tau=48 \mathrm{~h}$ it has landed and covers a range of longitudes centered around $20^{\circ} \mathrm{E}$ at $\tau=24 \mathrm{~h}$ (Fig. 6d) as the bean 
shape of the ridging anticyclone is at its advanced stage of formation (Fig. 3d) just before it breaks off. The high pressure system that has broken off has a positive anomaly associated with it and continues to be coupled to the eastward propagating positive stratospheric anomaly, as the Rossby waves continue breaking and dissipating after $\tau=48 \mathrm{~h}$. This behavior is again climatological and it is observed for all the composites, except for the short-lived events.

Finally, the PV anomalies extend from above the $350-\mathrm{K}$ isentropic surface in the lower stratosphere to the midlatitude dynamical tropopause but decrease in strength as they approach this level (Fig. 6), which is close to the $250-\mathrm{hPa}$ isobaric surface. For the annual average the tropopause pressure in the midlatitudes of the $\mathrm{SH}$ is about $250 \mathrm{hPa}$ (Hoinka 1998), as confirmed also by the intersection between the PV $=-2 \mathrm{PVU}$ and $330-\mathrm{K}$ isentrope [see Fig. 1 in Ndarana and Waugh (2011)], as well as the thick dashed white contour, representing PV $=-2$ PVU in Fig. 6. Note that the undulations in this contour are consistent with the vertical PV anomaly structure. This means that the strongest PV anomalies are located above the tropopause. It may then be concluded that the vertical structure of the PV anomalies suggests that the wave breaking that is associated with ridging anticyclones, as discussed in the previous subsections, has a three-dimensional structure but it is weakest (or vanishes) just above the tropopause. The diminishing strength of the PV anomalies near the $250-\mathrm{hPa}$ level is consistent with the climatological structure of the midlatitude dynamical tropopause (see thick white contour in Fig. 3), which as noted previously is perturbed but does not show as much overturning on average as PV in the lower stratosphere. This confirms the aforementioned suggestion that the RWB that is associated with (or that it is important for) ridging anticyclones is indeed predominantly a lower-stratospheric phenomenon.

\section{c. Horizontal view of the low-level PV anomaly}

To have a slightly better appreciation of the structure, dynamics, and possible role of the surface negative PV anomaly that forms, as discussed above, the horizontal PV anomaly field at $1000 \mathrm{hPa}$ (shaded) and MSLP (thick dashed black contours) are examined. These are presented in Fig. 7, which should be interpreted in conjunction with Figs. 3 and 6. In Fig. 7 the areas of statistical significant levels of $95 \%$ are indicated by the hatching.

There are three centers of negative PV anomalies that are observed at $1000 \mathrm{hPa}$. The PV anomaly of interest at this point is climatologically located on the west coast of the subcontinent (i.e., the Namibian west coast). This is a robust feature as indicated by the $95 \%$ statistical significance level (left-tilted hatching). As the ridging occurs (represented here only by the 1018-, 1020-, and 1022-hPa contours of the mean sea level pressure; thick dashed contours in black) this anomaly extends southward, following the structure of the coast. The leading edge of this extension arrives in the Cape Town area as the bean shape of the anticyclone forms. Note that regions with negative anomalies stronger than $-0.1 \mathrm{PVU}$ are the darker shaded regions in gray enclosed by the thin black contour. The region of the bean shape that curves southward is a trough and it is therefore characterized by cyclonic flow [see also examples in Crimp and Mason (1999) and Blamey and Reason (2009)].

The source of the preexisting Namibian west coast anomaly is unknown at this time and requires further investigation. A preliminary hypothesis is that it might be a coastally trapped Kelvin wave that is generated by unusually large southwestward flow around a heat low over Namibia. Note also that the question of how it extends southward (Figs. 7d-f) cannot be answered without the benefit of the vertical profiles of the previous subsection. On this basis we hypothesize that this extension is caused by the high-level negative PV anomaly that is lowered by isentropic transport of high-PV air facilitated by RWB in the lower stratosphere as it propagates eastward. Furthermore, when the low-level negative PV anomaly reaches the Cape Town area, it induces the cyclonic flow that characterizes the bean shape of the ridging high pressure system.

The breaking off of the ridging anticyclone is also induced by the closed low-level positive anomaly (see light-shaded enclosed structure south of South Africa) that forms more or less where the break off occurs. This anomaly is statistically significant right the evolution of the composites (see left-tilted hatching). We propose that the positive anomaly induces an anticyclonic circulation within the bean-shaped ridging anticyclone at $\tau=24 \mathrm{~h}$ (Fig. $7 \mathrm{~d}$ ), so that the break off takes place. Note that this closed anomaly precedes the break off. Again this low-level positive PV anomaly is coupled with the stronger one located in the lower stratosphere and so its eastward propagation is influenced by lowerstratospheric wave breaking. The influence of stratospheric anomalies on surface process is actually not unreasonable nor is it an infeasible hypothesis. Jeong et al. (2006) demonstrated that a stratospheric PV anomaly is capable of influencing a meteorological process at the surface, as also amply demonstrated in stratospheric-tropospheric coupling studies (e.g., Thompson et al. 2005).

A note on the other two negative PV anomalies is appropriate at this point. These are associated with 

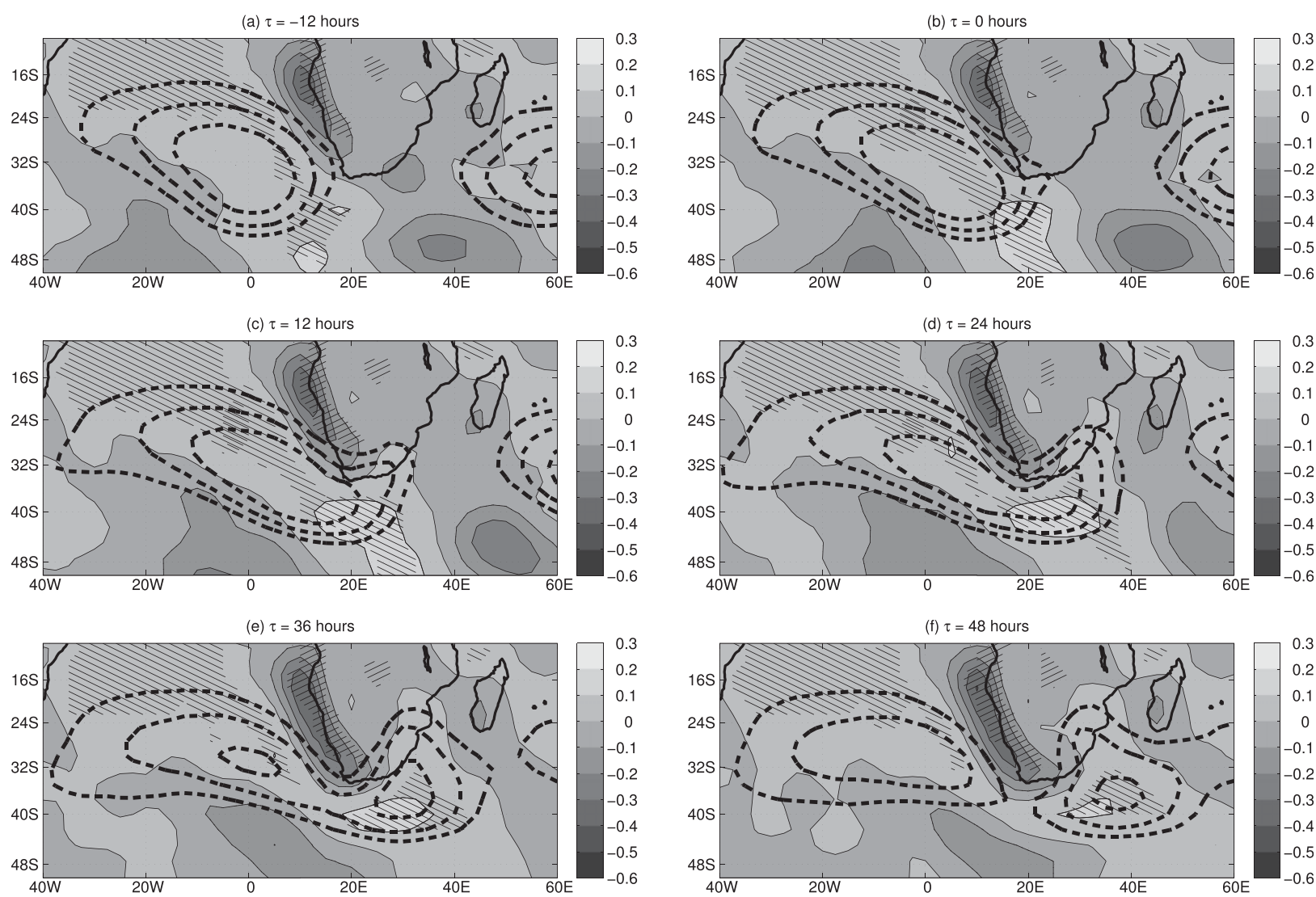

FIG. 7. Composites of PV anomalies (shaded; PVU) at $1000 \mathrm{hPa}$ (just above MSLP) associated with the ridging Atlantic Ocean anticyclones in Fig. 3 for $\tau=$ (a) -12 , (b) 0, (c) 12, (d) 24, (e) 36, and (f) $48 \mathrm{~h}$. The lighter (darker) shading represents areas of positive (negative) PV anomalies. The thick dashed black contours represent 1018, 1020, and $1022 \mathrm{hPa}$. Left (right)-tilted hatching denotes areas where positive (negative) negative anomalies are statistically significant at the $95 \%$ level.

midlatitude low pressure systems, which are illustrated in Fig. 3 (thin dashed black contours). Of particular interest between the two is the one located downstream, between $20^{\circ}$ and $60^{\circ} \mathrm{E}$, characterized by a low westerly wave low-cold front system, as previously mentioned. In essence the presence of this negative PV anomaly is informed by the fact that there would be a negative potential temperature anomaly here (Røsting and Kristjánsson 2012). This system propagates eastward to allow the ridging to occur but it does not appear to be playing any role in the context of the PV inversion-based hypotheses discussed above.

\section{d. Contrast with nonridging anticyclones}

For completeness, the results obtained above are compared with those cases that are confined to the Atlantic Ocean and do not undergo any ridging (see Fig. 8). Since the seasonal variations of Atlantic Ocean anticyclones that do not ridge are not the focus of this study, Fig. 8 was produced by merely taking the average of all the relevant cases (i.e., which are all those cases for which step 3 in section $2 b$ fails), regardless of season during which they occur. On average the anticyclones are associated with undulating PV contours (i.e., line wave propagation) in the lower stratosphere and the dynamical tropopause. The latter is, of course, to be expected, since it is also the case for ridging anticyclones. It is clear that on average that nonridging

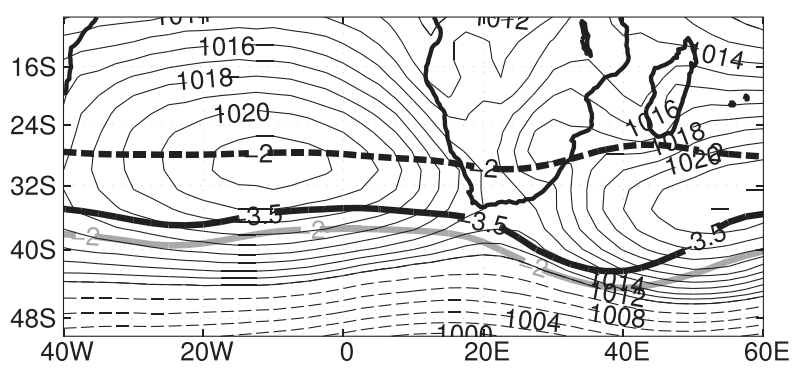

FIG. 8. Time average of nonridging Atlantic Ocean anticyclones produced by the mean of all Atlantic anticyclones minus all the cases that extend eastward beyond $25^{\circ} \mathrm{E}$ meridian. Contours as in Fig. 3. 
anticyclones have no RWB connection; if anything, the lower-stratospheric anomalies are extremely weak, as informed by the zonally symmetric structure of the PV contours.

\section{Discussion and concluding remarks}

Using 36 years of NCEP-2 data, the vertical coupling of ridging anticyclones to lower-stratospheric Rossby wave breaking has been established. A three-dimensional picture emerges from the above discussion.

- Anticyclonic barotropic shear (Peters and Waugh 1996, 2003) in the lower stratosphere, on the equatorward side of the eddy-driven jet core but south of the subtropical dynamical tropopause, causes propagating Rossby waves to break in the anticyclonic direction. The breaking facilitates the isentropic transport of high-PV air from the midlatitudes and low-PV air from the subtropics into this region. This results in the formation of alternating positive and negative PV anomalies.

- These PV anomalies are strongest in the lower stratosphere and couple the lower stratosphere with the discontinuous high pressure subtropical belt at the surface. The eastward propagation of breaking waves precedes the ridging process. The latter is further advanced by a low-level negative PV anomaly that originates along the Namibian coast, assisted by highPV air downstream in the vertical.

- A low-level positive PV anomaly forms over the ocean, south of the South Africa; by the same argument that applies to negative anomalies, it induces a localized anticyclonic flow inside the large-scale ridging high and causing the leading edge of it to break off and form an isolated high pressure system. This new structure is integrated into the Indian Ocean high pressure system.

- The wave-breaking signal lasts for as long as the ridging continues to occur, and it dissipates as the broken-off portion of the ridging anticyclone amalgamates with the Indian Ocean high pressure system (Tyson and Preston-Whyte 2000), which is an indication of the end of the life cycle of the ridging high (see the introduction and Fig. 1). It appears that wave breaking influences the longevity of the ridging process because the PV anomalies that inform the ridging are dismantled at this point and decoupling between the lower stratosphere and the surface occurs.

These conclusions apply to all cases that have a duration that is longer than $24 \mathrm{~h}$. Similar composites to the ones presented here were analyzed. The evolution structure revealed by the case presented here is in agreement with composites of the other cases, except for the shorter-lived events (i.e., $\leq 1$ day). The difference of course is the fact that for the longer cases, the wave breaking lasts longer and is sometimes observed on PV contours that are slightly higher than the ones shown in Fig. 4 (e.g., PV $=-4.5$ PVU). For such cases, the midlatitude dynamical tropopause is more perturbed than the gray contour shown in Fig. 3. The shorter-lived events merely show undulations in the PV contours (similar to those shown in Fig. 8).

The study has provided evidence that wave breaking plays an important role in ridging Atlantic Ocean anticyclones; however, there is need for further study of the events. This could include idealized modeling using a dynamical core (e.g., Hitchcock et al. 2013) and PV tendency analysis (e.g., Wu and Wang 2000; Tamarin and Kaspi 2016) that should include PV inversion (e.g., Davis and Emmanuel 1991; Davis 1992; Black and Dole 1993; Hakim et al. 1996; Huo et al. 1999; Brennan et al. 2008; Kieu and Zhang 2010; Røsting and Kristjánsson 2012). It is envisaged that the PV tendency analysis will shed some light on the southward extension of Namibian PV anomaly and exactly how it induces the cyclonic flow. Finally, the presence of this Namibian PV anomaly is poorly understood. Further analysis of its causes should also be investigated. A preliminary hypothesis is that it is a signature of a coastally trapped Kelvin wave.

Acknowledgments. We thank Dr. Anne Rechou and two other reviewers for comments and suggestions that improved the manuscript. We also thank Dr. Andries Kruger for his helpful thoughts on statistical aspects of the analysis. This research was partially funded by the Water Research Commission of South Africa.

\section{REFERENCES}

Berrisford, S., B. J. Hoskins, and E. Tyrlis, 2007: Blocking and Rossby wave breaking on the dynamical tropopause in the Southern Hemisphere. J. Atmos. Sci., 64, 2881-2898, https:// doi.org/10.1175/JAS3984.1.

Black, R. X., and R. M. Dole, 1993: The dynamics of large-scale cyclogenesis over the North Pacific Ocean. J. Atmos. Sci., 50, 421-442, https://doi.org/10.1175/1520-0469(1993)050<0421: TDOLSC $>2.0 . \mathrm{CO} ; 2$.

Blamey, R. C., and C. J. C. Reason, 2009: Numerical simulation of a mesoscale convective system over the east coast of South Africa. Tellus, 61, 17-34, https://doi.org/10.1111/ j.1600-0870.2008.00366.x.

Brennan, M. J., G. M. Lackman, and K. M. Mahoney, 2008: Potential vorticity (PV) thinking in operations: The utility of nonconservation. Wea. Forecasting, 23, 168-182, https://doi.org/ 10.1175/2007WAF2006044.1.

Brown, T. J., and B. L. Hall, 1999: The use of $t$ values in climatological composite analyses. J. Climate, 12, 2941-2944, https://doi.org/ 10.1175/1520-0442(1999)012<2941:TUOTVI >2.0.CO;2. 
Charney, J. G., 1947: The dynamics of long waves in a baroclinic westerly current. J. Meteor., 4, 136-163, https://doi.org/ 10.1175/1520-0469(1947)004<0136:TDOLWI >2.0.CO;2.

Cook, C., C. J. C. Reason, and B. C. Hewitson, 2004: Wet and dry spells within particularly wet and dry summers in the South African summer rainfall region. Climate Res., 26, 17-31, https:// doi.org/10.3354/cr026017.

Crimp, S. J., and S. J. Mason, 1999: The extreme precipitation event of 11 to 16 February 1996 over South Africa. Meteor. Atmos. Phys., 70, 29-42, https://doi.org/10.1007/s007030050023.

Davis, C. A., 1992: Piecewise potential vorticity inversion. J. Atmos. Sci., 49, 1397-1411, https://doi.org/10.1175/1520-0469(1992)049<1397: $\mathrm{PPVI}>2.0 . \mathrm{CO} ; 2$.

—_, and K. A. Emmanuel, 1991: Potential vorticity diagnosis of cyclogenesis. Mon. Wea. Rev., 119, 1929-1953, https://doi.org/ 10.1175/1520-0493(1991)119<1929:PVDOC > 2.0.CO;2.

Engelbrecht, C. J., W. A. Landman, F. A. Engelbrecht, and J. Malherbe, 2015: A synoptic decomposition of rainfall over the Cape south coast of South Africa. Climate Dyn., 44, 2589-2607, https://doi.org/10.1007/s00382-014-2230-5.

Gabriel, A., and D. Peters, 2008: A diagnostics study of different types of Rossby wave breaking in the Northern Hemisphere. J. Meteor. Soc. Japan, 86, 613-631, https://doi.org/10.2151/ jmsj.86.613.

Hakim, G. J., D. Keyser, and L. F. Bosart, 1996: The Ohio Valley wave-merger cyclogenesis event of 25-26 January 1978. Part II: Diagnosis using quasigeostrophic potential vorticity inversion. Mon. Wea. Rev., 124, 2176-2204, https://doi.org/ 10.1175/1520-0493(1996)124<2176:TOVWMC>2.0.CO;2.

Hitchcock, P., T. G. Shepherd, M. Taguchi, S. Yoden, and S. Noguchi, 2013: Lower-stratosphere radiative damping and polar-night jet oscillations events. J. Atmos. Sci., 70, 1391-1408, https://doi.org/ 10.1175/JAS-D-12-0193.1.

Hoinka, K. P., 1998: Statistics of the global tropopause pressure. Mon. Wea. Rev., 126, 3303-3325, https://doi.org/10.1175/ 1520-0493(1998)126<3303:SOTGTP>2.0.CO;2.

Holton, J. R., 2004: An Introduction to Dynamic Meteorology. 4th ed. Elsevier Academic Press, 553 pp.

Hoskins, B. J., 1991: Towards a PV- $\theta$ view of the general circulation. Tellus, 43B, 27-35, https://doi.org/10.3402/tellusb.v43i4.15396.

- M. E. McIntyre, and A. W. Robertson, 1985: On the use and significance of isentropic potential vorticity maps. Quart. J. Roy. Meteor. Soc., 111, 877-946, https://doi.org/10.1002/ qj. 49711147002

Huo, Z., D. Zhang, and J. R. Gyakum, 1999: Intersection of potential vorticity anomalies in extratropical cyclogenesis. Part I: Static piecewise inversion. Mon. Wea. Rev., 127, 2546-2562, https://doi.org/ 10.1175/1520-0493(1999)127<2546:IOPVAI >2.0.CO;2.

Jeong, J.-H., B.-M. Kim, C.-H. Ho, D. Chen, and G.-H. Lim, 2006: Stratospheric origin of a cold surge occurrence in East Asia. Geophys. Res. Lett., 33, L14710, https://doi.org/10.1029/2006GL026607.

Jones, D. A., and I. Simmonds, 1994: A climatology of Southern Hemisphere anticyclones. Climate Dyn., 10, 333-348, https:// doi.org/10.1007/BF00228031.

Jury, M. R., 2014: Environmental forcing of red tides in the Southern Benguela. Int. J. Oceanogr., 325321, https://doi.org/ 10.1155/2014/325321.

Kanamitsu, M., W. Ebisuzaki, J. Woollen, S. K. Yang, J. Hnilo, M. Fiorino, and G. L. Potter, 2002: NCEP-DOE AMIP-II Reanalysis (R-2). Bull. Amer. Meteor. Soc., 83, 1631-1643, https://doi.org/10.1175/BAMS-83-11-1631.

Kieu, C. Q., and D.-L. Zhang, 2010: A piecewise potential vorticity inversion algorithm and its application to hurricane inner-core anomalies. J. Atmos. Sci., 67, 2616-2631, https://doi.org/ 10.1175/2010JAS3421.1.

McIntyre, M. E., and T. N. Palmer, 1983: Breaking planetary waves in the stratosphere. Nature, 305, 593-600, https://doi.org/ $10.1038 / 305593 \mathrm{a} 0$.

Ndarana, T., and D. W. Waugh, 2011: A climatology of Rossby wave breaking on the Southern Hemisphere tropopause. J. Atmos. Sci., 68, 798-811, https://doi.org/10.1175/2010JAS3460.1.

Peters, D., and D. W. Waugh, 1996: Influence of barotropic shear on the poleward advection of upper-tropospheric air. J. Atmos. Sci., 53, 3013-3031, https://doi.org/10.1175/1520-0469(1996)053<3013: IOBSOT>2.0.CO;2.

$\longrightarrow$, and - 2003: Rossby wave breaking in the Southern Hemisphere wintertime upper troposphere. Mon. Wea. Rev., 131, 2623-2634, https://doi.org/10.1175/1520-0493(2003)131<2623: RWBITS $>2.0 . \mathrm{CO} ; 2$.

Postel, G. A., and M. H. Hitchman, 1999: A climatology of Rossby wave breaking along the subtropical tropopause. J. Atmos. Sci., 56, 359-373, https://doi.org/10.1175/1520-0469(1999)056<0359: $\mathrm{ACORWB}>2.0 . \mathrm{CO} ; 2$.

Røsting, B., and J. E. Kristjánsson, 2012: The usefulness of piecewise potential inversion. J. Atmos. Sci., 69, 934-941, https:// doi.org/10.1175/JAS-D-11-0115.1.

Rouault, M., A. M. Lee-Thorp, and J. R. E. Lutjeharms, 2000: The atmospheric boundary layer above the Agulhas Current during alongcurrent winds. J. Phys. Oceanogr., 30, 40-50, https://doi.org/ 10.1175/1520-0485(2000)030<0040:TABLAT >2.0.CO;2.

Schwendike, J., P. Govekar, M. J. Reeder, R. Wardie, G. J. Berry, and C. Jakob, 2014: Local partitioning of the overturning circulation in the tropics and the connection to the Hadley and Walker circulations. J. Geophys. Res. Atmos., 119, 1322-1339, https://doi.org/ 10.1002/2013JD020742.

Singleton, A. T., and C. J. C. Reason, 2007: A numerical study of an intense cut-off low pressure system over South Africa. Mon. Wea. Rev., 135, 1128-1150, https://doi.org/10.1175/MWR3311.1.

Song, J., C. Li, J. Pan, and W. Zhou, 2011: Climatology of anticyclonic and cyclonic Rossby wave breaking on the dynamical tropopause in the Southern Hemisphere. J. Climate, 24, 1239-1251, https:// doi.org/10.1175/2010JCLI3157.1.

Stander, J. H., L. Dyson, and C. J. Engelbrecht, 2016: A snow forecasting decision tree for significant snowfall over the interior of South Africa. S. Afr. J. Sci., 112, 29-38, https://doi.org/ 10.17159/sajs.2016/20150221.

Takaya, K., and H. Nakamura, 2001: A formulation of a phaseindependent wave-activity flux for stationary and migratory quasigeostrophic eddies on a zonally varying basic flow. J. Atmos. Sci., 58, 608-627, https://doi.org/10.1175/1520-0469(2001)058<0608: AFOAPI $>2.0 . \mathrm{CO} ; 2$.

Tamarin, T., and Y. Kaspi, 2016: The poleward motion of extratropical cyclones from a potential vorticity tendency analysis. J. Atmos. Sci., 73, 1687-1707, https://doi.org/ 10.1175/JAS-D-15-0168.1.

Tennant, W., 2004: Considerations when using pre-1979 NCEP/ NCAR reanalysis in the Southern Hemisphere. Geophys. Res. Lett., 31, L11112, https://doi.org/10.1029/2004GL019751.

Thompson, D. W., M. P. Baldwin, and S. Solomon, 2005: Stratosphere-troposphere coupling in the Southern Hemisphere. J. Atmos. Sci., 62, 708-715, https://doi.org/10.1175/ JAS-3321.1.

Tlhalerwa, K., M. T. Freiman, and S. J. Piketh, 2005: Aerosol decomposition off the Southern African west coast by Berg winds. S. Afr. Geogr. J., 87, 152-161, https://doi.org/10.1080/ 03736245.2005.9713838. 
Triegaardt, D. O., D. E. Terblanche, J. van Heerden, and M. V. Laing, 1988: The Natal flood of September 1987. South African Weather Bureau Tech. Paper 19, 62 pp. [Available from the South African Weather Service, Private Bag x097, Pretoria, 0001, South Africa.]

Tyson, P. D., and R. A. Preston-Whyte, 2000: The Weather and Climate of Southern Africa. Oxford University Press, 396 pp.

_ M. Garstang, R. Swap, P. Kallberg, and M. Edwards, 1996: An air transport climatology for subtropical South Africa. Int. J. Climatol., 16, 265-291, https://doi.org/10.1002/(SICI)1097-0088(199603)16: $3<265$ ::AID-JOC8>3.0.CO;2-M. van Heerden, J., and J. J. Taljaard, 1998: Africa and surrounding waters. Meteorology of the Southern Hemisphere, Meteor. Monogr., No. 49, Amer. Meteor. Soc., 141-174.

van Schalkwyk, L., and L. L. Dyson, 2013: Climatological characteristics of fog at Cape Town International Airport. Wea. Forecasting, 28, 631-646, https://doi.org/10.1175/ WAF-D-12-00028.1.

$\mathrm{Wu}$, L., and B. Wang, 2000: A potential vorticity tendency diagnostics approach for tropical cyclone motion. Mon. Wea. Rev., 128, 1899-1911, https://doi.org/10.1175/1520-0493(2000)128<1899: APVTDA $>2.0 . \mathrm{CO} ; 2$. 